\title{
THE PURSUIT OF GLOBAL MINDEDNESS AMONG MALAYSIAN HIGHER LEARNING INSTITUTIONS
}

\author{
Kalanithi Muthu ${ }^{1 *}$ and Shankar Chelliah ${ }^{2}$ \\ ${ }^{1}$ Sunway College, Malaysia \\ ${ }^{2}$ Universiti Sains Malaysia
}

\begin{abstract}
Globalization has various interpretations and it has been the rationale behind internationalizing higher education. Internationalization of higher education started in the past three decades globally. The term internationalization of higher education has been widely discussed in Malaysia in the past two decades. The survival and acceptance of Higher Learning Institution (HLI)s are highly dependent on how much elements of the internationalization are incorporated into these institutions. Even though Malaysian HLIs have spearheaded this effort a decade ago, it seems to be a goal far reaching for some HLIs. Despite internationalization efforts has been taken by Ministry of Higher Education Malaysia (MOHE), there is no significant and conclusive study on how HLIs in Malaysia are successful in meeting the global needs and requirements and what are the barriers that prohibiting Malaysian HLIs in achieving its internationalization goals. It is important to pay close attention to the development of Malaysian Higher Education System and the barriers towards internationalisation to be sustainable in global environment. This conceptual paper examines on the important factors in sustainability of higher education in Malaysia and proposes conceptual framework to study the important factors in pursuit of global mindedness among Malaysian HLIs.
\end{abstract}

Keywords: Internationalization, Higher Learning, Sustainability

\section{Introduction}

Higher education throughout the world has been going through major changes due to globalization. Higher Learning Institution (HLI)s around the world are facing challenges to equip with the demand from global market. Education is one of the key element in the global environment formation as it is the foundational to knowledge, the utilisation of technologies, cross border association and sustaining complex communities (Marginson \& van der Wende, 2007). Even international bodies have taken many initiative towards globalization. One of the initiative is by General Agreement on Trade in Services (GATS) which is part of World Trade Organization (WTO). GATS, member of WTO is obligated to open their market to each other in trading services and education is one of the services stated in GATS. Although Malaysia has been a WTO member since 1 January 1995, Malaysia did not commit to GATS. However, Malaysia has still taken initiatives towards globalization by focusing on internationalization of higher education since global context creates more opportunity and push to learn from more advanced technology and knowledge. Internationalization is seen as an important element to be focused on as part of globalization of higher education. The general definition discussed widely of internationalization of HLIs is the increasing importance of international involvement in the education component. In Malaysia, more emphasize is given to increase the global ranking of HLIs and less studies have been conducted on competitive approach of HLIs. This conceptual paper examines the important factors in the pursuit of global mindedness by giving the indicators which then is used in the conceptual framework.

\section{Global Context}

The character and impact of the term globalisation has been shaped by the developments in the past three decades and it is typically used either to characterize international spatial awareness or to highlight a 
transformation in the processes of interaction among individuals and groups (E \& Yildiz, 2012). In HLI context this groups are people from different parts of the world. Meanwhile attention focused on the intentional actions of individual, groups and social institutions as they actively seek to cross national borders in pursuit of social, economic, political or cultural benefits is internationalisation (E \& Yildiz, 2012). Thus, Internationalisation is the engine of globalisation.

There are many disagreements to GATS as education is seen as trade commodity. This leads to central question of what is the standard of internationalization that should be followed by higher education to be called as international education which caters to the globalization. There are also many different indicators on the global standards. There isn't any one that has been uniformed. Jane Knight has published many articles on Internationalization of Higher Education. Her definitions are adopted in many contexts of Higher education studies. Knight and de Wit (1997) view internalization as a meaningless term unless there is a strong emphasize on intercultural focused learning programs and curricula. As internationalization becomes an indicator for quality in higher education, quality of the internationalization is raising many debates. (Taylor, 2004). This shows that internationalization of higher education may have been looked at different context by different countries to justify the quality. In this study, internationalization is taken as part of important term that leads to the pursuit of global mindedness among HLIs in Malaysia.

\section{Malaysian higher learning context}

Malaysian government initiatives have looked into considerable efforts to include sustainable development agents in higher education system in Malaysia but many aspects of sustainability are not included yet (Reza,2016). Number of students choosing overseas as their study destination for business courses are rising (Naidu \& Derani, 2016). There are four factors in current trend in Malaysian higher education, namely globalisation, teaching and learning, governance and knowledge based society (Grapragasem et al.,2014). Figure 5.1 shows the number of HLIs in Malaysia in 2016. There are currently 20 public universities, 34 polytechnics, 94 public community colleges, 52 private universities, 10 foreign university branch campuses and about 433 active private colleges in Malaysia. Besides that, various other educational institutions from the UK, US, Australia, Canada, France, Germany and New Zealand offer twinning and franchised degree programs through partnerships with Malaysian colleges and universities (Ministry of Higher Education, 2009).

The highly globalized sectors of the economies require that students have to become creative, innovative and flexible to be able to find new solutions to new problems besides just learning basics (Adler, 1992). HLIs in Malaysia face new pressures and demands for accountability, access, quality, and the introduction of new technologies and curricular. The role of teacher will be a facilitator role in 2023 as out of classroom learning will be more important (Ongoz \& Baki, 2010). Distance learning and online learning are technology platforms that are replacing traditional classroom in global environment. Some HLIs has taken their initiative to face the changes. For example, University Putra Malaysia(UPM) has embarked on Open Educational Resources and Putra Massive Open Online Course (Putra MOOC) in their Strategic Plan 2014-2020. In New Media Consortium(NMC) Report 2017, 6 key trends accelerating higher education which is driving technology adoption in Higher education is highlighted. Blended learning designs and Collaborative designs were identified for short term. Growing Focus on Measuring Learning and Redesigning Learning Spaces for midterm. Advancing Cultures of Innovation and Deeper Learning Approaches for Long Term. All of these are directly related to technologies used in Higher Education in the globalised environment.

The quality of higher education in Malaysia is governed through the Malaysian Qualification Agency(MQA). MQA is responsible to take care of the quality assurance and accreditation of courses and functions in both public and private university in Malaysia. Malaysian HLI are also well regulated with legislations such as The Education Act 1996 (Act550), The Private Higher Educational Institutional Act 1996(amended 2009), The National Council of Higher Education Act 1996, Malaysian Qualification Agency Act 2007, The Universities 
and University Colleges Act 19969Amended 2009) and The National Higher Education Fund Corporation Act 1997(Amendment 2000).

In the recent $14^{\text {th }}$ General Election(GE14) of Malaysia, the government has changed after 61years and Mazlee Malik is appointed as the new Education Minister of Malaysia. It is believed new changes will arise to the Higher Education system with this change in Cabinet. However, in one of his statement released by local press, he stated that he will not make any major changes to the HLIs as any major changes made now will affect HLIs current world ranking.

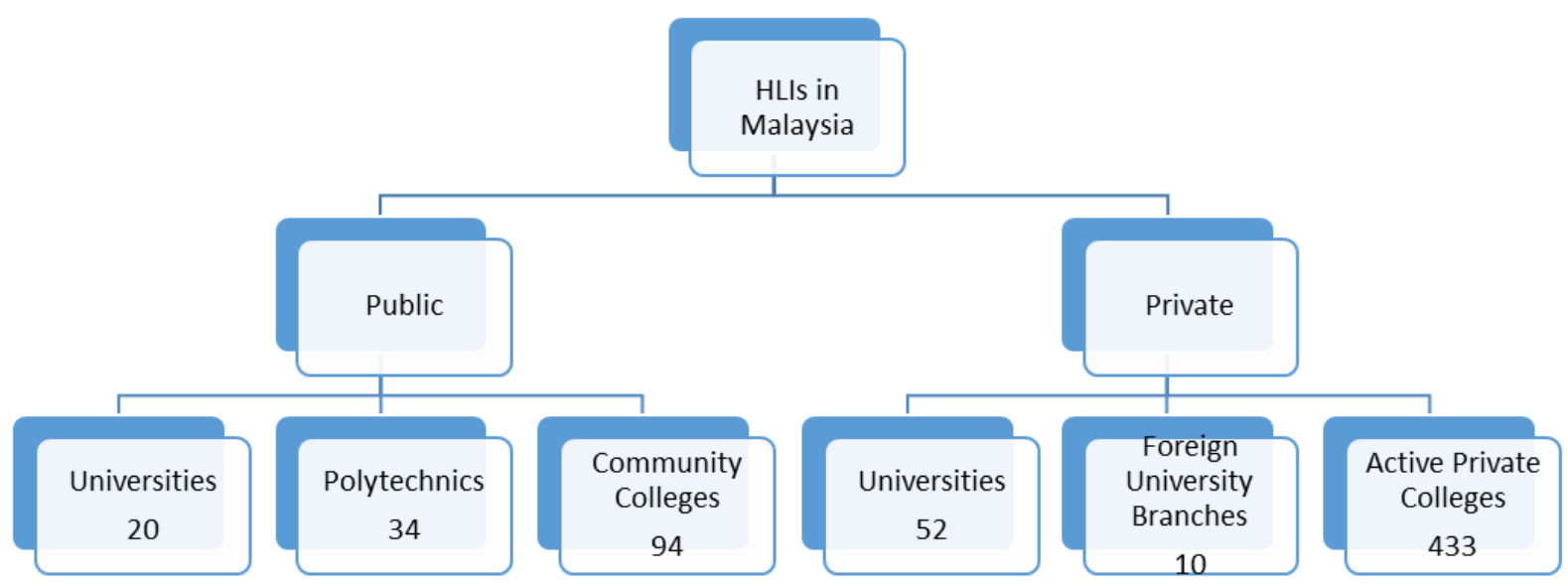

Figure 1: Number of Higher Education Institutions in Malaysia in 2017

(Source: StudyMalaysia.com)

"The education business provides a major stream of income to the national GDP, and the Malaysian government has given considerable attention to developing this sector" (Grapragasem et al.,2014) Thus it is important to pay close attention to the development of Malaysian Higher Education System and the barriers towards internationalisation to be sustainable in global environment.

There are several studies showing different indicators for internationalisation of Higher Education. It is important to compare and contrast all these indicators and develop a new indicator as a what is accepted globally. Malaysia often look at Western countries HLIs as benchmark but it is important to also look at other cross border countries that has been successful in their education such as China as with globalisation USA is no longer seen as the dominance of the world economy. By looking at this then, barriers to internationalisation will be identified. It can be seen what are the similarities and differences between Malaysia and other countries HLIs towards internationalisation and also against the globally accepted internationalisation standards based on the newly developed indicators. Based on the Literature Review, five determinates of HLI Internationalisation are identified and used to develop Conceptual Model as shown on Figure 2. 


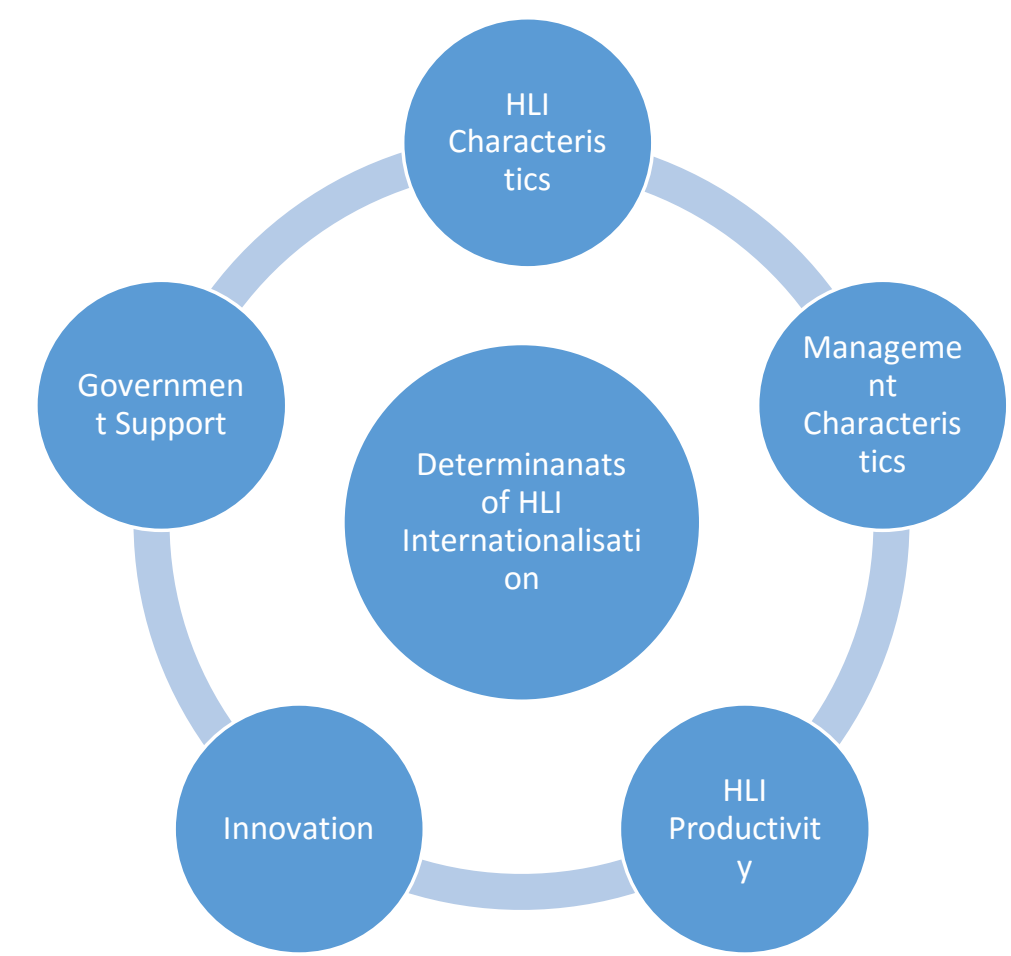

Figure 2 Conceptual Model: Determinants of HLI Internationalisation

\section{Internationalisation Integration in HLIs}

The process of internationalisation is a continuous cycle. Knight has developed internationalisation cycle which consists of six steps process: awareness, commitment, planning, operationalise, review and reinforcement (Knight, 1994).

Figure 3 shows the process of internationalisation cycle by Knight. The six process involves commitment from management and faculty. In order to make the six process a success in HLIs context, there need to be a support from both internal and external parties or players in the HLIs. This has to be a continuous support to be successful in internationalisation. 


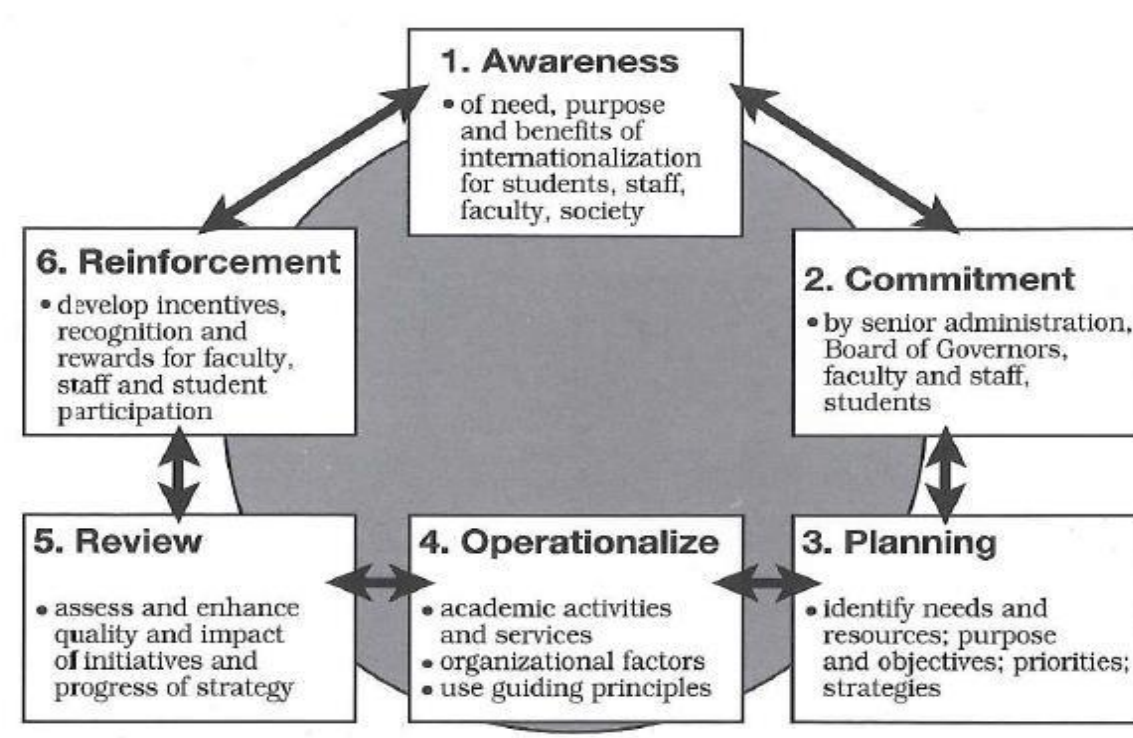

\section{Internationalization Cycle}

Supportive Culture to Integrate Internationalization

Figure 3 Internationalisation cycle

(Knight, 1994)

\section{HLI and Management Characteristics}

HLI characteristics refers to size of HLI, length of establishment and the level of technology adoption. Size and scale and financial and physical resources are some of the internal barriers for internationalisation (Sekliuckiene, 2013). These characteristics are important as a higher level characteristic may be able to achieve internationalisation earlier than institutions with lower characteristics. Financial is shown as a barrier for internationalisation in a study of SME in India (Roy, Sekhar, \& Vyas, 2016). A lower financial strength can prevent internationalisation efforts by the institution. Technology level is another factor that fall sunder HLI Characteristics. According to UNESCO (2002), ICT now permeates the education environments and underpins the very success of 21 st century education and adds value to the learning process as well as to the organization and management of learning institutions. It is also the driving force behind development and innovation in developed and developing countries (Talebian, Mohammadi, \& Rezvanfar, 2014). Effective ICT implementation enables speed, cost-saving, transcendence of time and distance, opportunities for cross-culture learning, extension of international relationships, adoption of quality international standards and strengthen ties with institutions abroad (Magsan \& Aleksic-Maslac, 2009). The absence of technological knowledge will hinder firm's internationalisation in the competitive marketplace (Xie \& Suh, 2014). Length of establishment is another important determinant in ability to deal with internationalisation efforts. General attitude towards work of the members of an organization has an importance in the manner of work effectively carried out along with the individual and organizational outcomes. Prior findings show employees with positive attitudes tend to be more productive. (Bentea, 2015). Managerial barriers were one of the prominent obstacle in the pursuit of internationalisation and that includes lack of knowledge ((Roy et al., 2016). On the basis of above discussion, the following hypothesis are proposed:

H1. HLI characteristics have significant influence towards Internationalization of HLI in Malaysia 
H2. Management characteristics of HLI have significant influence towards Internationalization of HLI

\section{HLI Productivity \& Innovation}

Internationalisation requires employees within the HLI to be competent to meet the global demand. It is a challenge to many particularly teachers in HLI. Directing values or ethos, diversifies teaching and learning environment and mobility are among the orientations identifies in the matrix of six multifaceted contextual factors towards internationalisation (Korhonen \& Weil, 2015). A preliminary study in a public Institution of Higher Education in Malaysia shows organizational performance is highly associated with continuous learning (Hussein, Omar, Noordin, \& Ishak, 2016). Employee's behaviour, for example willingness to learn can contribute to continuous learning. One of the strength of HLI internationalisation system is innovation led growth (Alsharari, 2018). In a HLI context here, this can only be achieved if the HLI supports process and product innovation. Succeed of academic spin offs in the international market depends on the development of practices designed to stimulate academic entrepreneurship (Franco-Leal, Soetanto, \& Camelo-Ordaz, 2016). This is important as part of survival of HLI in internationalisation context depends on the level of innovation. With this discussion the following hypothesis are developed:

H3. HLI productivity have significant influence towards Internationalization of HLI

H4. Innovation activities pursued by HLI have significant influence towards Internationalization of HLI

\section{Government Support}

Government support plays a vital role in success of HLIs in the country. The emergence of some world class institutes of education in UAE is part of the result of Emirates government's establishment of authorities as governing bodies to ensure education quality (Alsharari, 2018). In the study conducted in India, among the highest obstacle towards SME internationalisation are the procedural and currency barriers. This can also be applicable to internationalisation of HLI. Governmental and economic political or legal barriers and procedural and currency barriers are two of the external barriers identified by Roy in his study of internationalisation (Roy et al., 2016). Less government funding is one of the multiple themes that fall under the banner of globalisation of higher education (McCann, 2014).

Following the above discussion additional hypothesis were developed to include the external factors in the Global Mindedness Model that perceived high government support will have a positive relationship with HLI Characteristics, Management Characteristics, HLI Productivity and Innovation towards internationalisation. In this context, government is identified as moderating role in the internationalisation of HLI.

H5. The significant positive relationship between HLI Characteristics and internationalization of HLI is perceived to be higher with government support

H6. The significant positive relationship between Management Characteristics and internationalization of HLI is perceived to be higher with government support

H7. The significant positive relationship between HLI Productivity and internationalization of HLI is perceived to be higher with government support

H8. The significant positive relationship between Innovation Activities and internationalization of HLI is perceived to be higher with government support 


\section{Research Framework}

The hypothesis developed from the above study contributed to the research framework as shown on Figure 4. Global Mindedness is grouped into four variables in the research framework. The four variables are HLI Characteristics, Management Characteristics, HLI Productivity and Innovation Activities which are categorised as Direct Variables. As Internationalisation is the engine of Globalisation in HLI, these four variables have significant relationship with HLI Internationalisation. Government support is the moderating variable which is important as the Direct Variables is perceived to higher with the support of moderating variable.

Global Mindedness

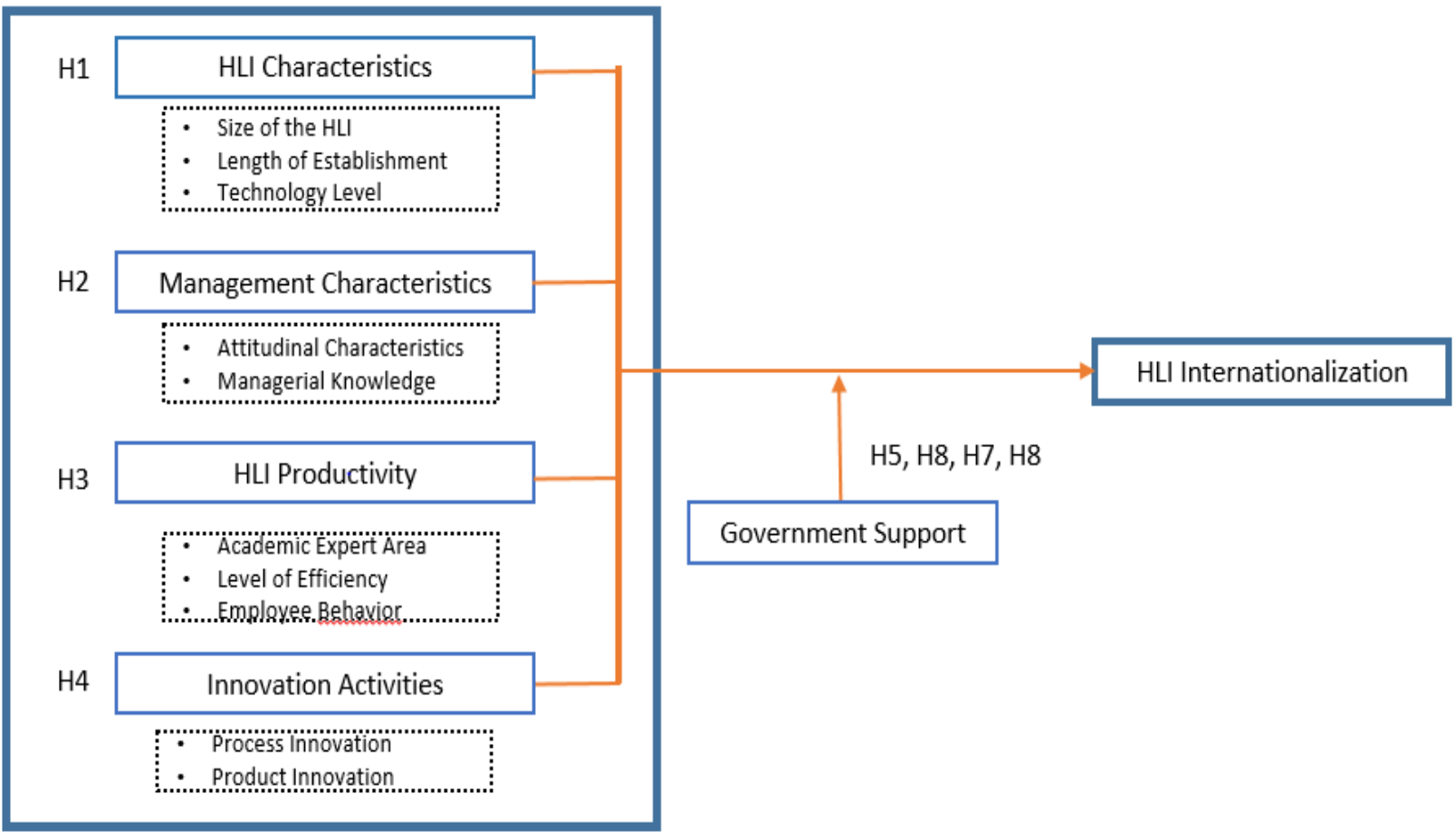

Figure 4 Research Framework

\section{Methodology}

The proposed methodology for this study is using qualitative technique. Qualitative method, through the use of questionnaires will be applied to gather the factors that affect the pursuit of global mindedness. This questionnaire will be sent to all the academicians in Malaysian Higher Learning Institutions to record the responses. Likert scale will be used to assess the factors within global mindedness that affects the organizations performance towards internationalisation.

\section{Conclusion and Limitations}

The above conceptual paper indicates that there are five important determinants in the pursue of global mindedness among Malaysian HLIs. As highlighted in the paper the five determinants are, HLI Characteristics, Management Characteristics, HLI Productivity, Innovation Activities and Government Support. In order to be successful in internationalisation of Malaysian HLIs, it is important to pay attention to Knight's internationalisation cycle and it can only be successful if the barriers from the five highlighted determinants are 
analysed and applied in the HLIs efforts towards internationalisation which leads to the pursue of global mindedness.

This paper has only outlined Government as moderating barrier, as only the direct barriers has been taken into consideration. However, market condition such as intense competition and various customers' expectations may also affect the internationalisation of HLIs in Malaysia. This research could further be expanded to study on how market conditions affects the performance of HLIs in Malaysia. It also would be interesting to understand on how customers from different cultures affect the internationalisation process.

This research gives many potential benefits. Previous researches have not highlighted barriers faced from this factors. Thus this research will be useful for policy makers and can be used to develop appropriate strategies by Malaysian HLIs upon studying the result from the research.

\section{References}

Adler, P.S. (1992). “Introduction.” In P. S. Adler (ed.). Technology and the Future of Work, New York: Oxford University Press

Alsharari, N. M. (2018). Internationalization of the higher education system: an interpretive analysis. International Journal of Educational Management, 32(3), 359-381. doi:10.1108/ijem-04-2017-0082

Bentea, C.-C. (2015). Relationships between Personality Characteristics and Attitude Towards Work in School Teachers. Procedia - Social and Behavioral Sciences, 180, 1562-1568. doi:10.1016/j.sbspro.2015.02.307

E, D., \& Yildiz, S. (2012). Internationalization and Globalization in Higher Education. In Globalization Education and Management Agendas.

Franco-Leal, N., Soetanto, D., \& Camelo-Ordaz, C. (2016). Do they matter? The role of non-academics in the internationalization of academic spin-offs. Journal of International Entrepreneurship, 14(3), 410-440. doi:10.1007/s10843-016-0184-x

Grapragasem, S, Krishnan, A., Mansor, A.N. (2014). Current Trends in Malaysian Higher Education and the Effect on Education Policy and Practice: An Overview, International Journal of Higher Education, Vol. 3, No. 1; 2014.

Hussein, N., Omar, S., Noordin, F., \& Ishak, N. A. (2016). Learning Organization Culture, Organizational Performance and Organizational Innovativeness in a Public Institution of Higher Education in Malaysia: A Preliminary Study. Procedia Economics and Finance, 37, 512-519. doi:10.1016/s2212-5671(16)30159-9

Knight, J. (1994). Internationalization: Elements and checkpoints, Canadian Bureau for International Education. Ottawa, Canada: CBIE

Knight, J. and de Wit, H., 1997, Internationalisation of HE in Asia Pacific countries, European Association for International Education, Amsterdam

Korhonen, V., \& Weil, M. (2015). The internationalisation of higher education: Perspectives on self-conceptions in teaching. Journal of Research in International Education, 14(3), 198-212. doi:10.1177/1475240915615447

Magzan, M. and Aleksic-Maslac, K. (2009), "ICT as an effective tool for internationalization of higher education", The 13th Multi-conference on Systemics, Cybernetics and Informatics: WMSCI, Academic Globalization: AG 2009, Orlando, FL, July 10-13.

Marginson, S. and M. van der Wende (2007), "Globalisation and Higher Education", OECD Education Working Papers, No. 8, OECD Publishing, Paris. http://dx.doi.org/10.1787/173831738240

McCann, P. (2014). Keys to the City: How Economics, Institutions, Social Interaction, and Politics Shape Development, by Michael Storper. 2013. Princeton, New Jersey and Oxford, U.K.: Princeton University Press. $275+\mathrm{x}$. ISBN 978-0-69114-311-8, \$39.95. Journal of Regional Science, 54(3), 524-527. doi:10.1111/jors. 12128

Naidu, P. \& Derani, N.E.S. (2016). A Comparative Study on Quality of Education Received by Students of Private Universities versus Public Universities. Procedia Economics and Finance 35(2016), $659-666$. 
Ongoz, S. \& Baki, B. (2010). The opinions of lecturers about the state of education and instructional technologies by the year 2023, Procedia Social and Behavioral Sciences 9(2010), 628-632.

Reza, M. I. H. (2016). Sustainability in higher education: Perspectives of Malaysian higher education system. SAGE Open, 6(3). DOI: 10.1177/2158244016665890

Roy, A., Sekhar, C., \& Vyas, V. (2016). Barriers to internationalization: A study of small and medium enterprises in India. Journal of International Entrepreneurship, 14(4), 513-538. doi:10.1007/s10843-016-0187-7

Services, W. (2017). Higher Education in Malaysia - StudyMalaysia.com. StudyMalaysia.com. Retrieved 22 September 2017, from https://www.studymalaysia.com/education/higher-education-in- malaysia

Sekliuckiene, J. (2013). Lithuanian Companies in Emerging Markets: Internationalization Motives and Barriers. Economics and Management, 18(1). doi:10.5755/j01.em.18.1.3782

Talebian, S., Mohammadi, H. M., \& Rezvanfar, A. (2014). Information and Communication Technology (ICT) in Higher Education: Advantages, Disadvantages, Conveniences and Limitations of Applying E-learning to Agricultural Students in Iran. Procedia - Social and Behavioral Sciences, 152, 300-305. doi:10.1016/j.sbspro.2014.09.199

Taylor, J. (2004). Towards a strategy of internationalization: Lessons and practice from four universities, Journal of Studies in International Education, 8 (2), 149-171.

Xie, Y. H., \& Suh, T. (2014). Perceived resource deficiency and internationalization of small- and mediumsized firms. Journal of International Entrepreneurship, 12(3), 207-229. doi:10.1007/s10843-014-0121-9 